\title{
The role of management's tendency and personnel's motivation in fulfillment of brand promise
}

\author{
Mahmoud Samiei Nasr ${ }^{\mathrm{a}}$, Seyed Mohsen Mahmoudzadeh ${ }^{\mathrm{a}^{*}}$, Seyed Shahab Mousavi ${ }^{\mathrm{a}}$ and Azadeh \\ Boostani $^{b}$
}

${ }^{a}$ Department of Management and Accounting, South Tehran Branch, Islamic Azad University,Tehran, Iran ${ }^{b}$ MA student at Islamic Azad University (IAU), Kish International Branch, Kish, Iran

\section{H R O N I C L E}

\begin{tabular}{l}
\hline Article history: \\
Received December 2, 2013 \\
Accepted 8 May 2014 \\
Available online \\
May 212014 \\
\hline Keywords: \\
Brand Promise \\
Personnel's Will and Interest \\
Motivation \\
TAM Iran Khodro
\end{tabular}

\section{Introduction}

Building a good brand plays essential role for the success of most organizations and it is important to create a good image on customer's mind about a product's identity. There are literally several studies associated with brand promise. Abbasi et al. (2014) investigated the effects of four components of organizational culture on brand promise in one of Iranian producer of detergent and sanitary products. They detected that three components of organizational culture including tribal culture, entrepreneurial culture, and market culture influenced positively on brand promise and bureaucratic culture influences negatively on brand promise. Aziziha et al. (2014) investigated the impact of various conflict management strategies including competition, cooperation, prevention and compromise on brand promise. They applied the questionnaire developed by Putnam and Wilson (1982) to measure conflict management measures and to measure the components of brand promise, the study develops

\begin{abstract}
Fulfillment of the promises or brand promise plays essential role for the success of organizations. This paper presents an empirical investigation to evaluate the rate of management's interest and personnel's motivation in an Iranian firm named TAM Iran Khodro. The study reviews its relationship with fulfillment of corporative promises for customers. The selects a sample of 206 employees of TAM Iran Khodro Company including manage With respect to primary sample group including 40 participants, Cronbach's Alpha coefficient was calculated as 0.905 for reliability value of this questionnaire, which validates the questionnaire. Spearman's correlation coefficient and multiple regressions have been adopted to test different hypotheses. Research findings indicate that management's tendency and personnel's motivation were positively and significantly associated with fulfillment of corporative promises to customers (Brand Promise) with correlation coefficient 0.427 .
\end{abstract}

C 2014 Growing Science Ltd. All rights reserved.

\footnotetext{
*Corresponding author. Tel: +989177371657

E-mail addresses: mohsenmahmoudzadeh@gmail.com (S. M. Mahmoudzadeh) 
a questionnaire. Using Pearson correlation ratios as well as multiple regression technique, the study detected that there was a reverse relationship between two conflict management strategies, cooperation and compromise, and brand promise. They also reported that there was a positive relationship between two conflict management strategies, competition and compromise, and brand promise. Azad et al. (2013) presented factor analysis to determine the most important factors in building a national brand. They applied factor analysis to extract the most influencing factors and the sample size was chosen from two major automakers in Iran called Iran Khodro and Saipa. They provided six factors including “cultural image of customers”, “exciting characteristics”, "competitive pricing strategies”, “perception image” and "previous perceptions”.

\section{The proposed study}

The proposed study of this paper examines the effects of management's tendency and employees' motivation on customers of an Iranian firm named TAM Iran Khodro. The main hypothesis of this survey is as follows,

Main hypothesis: Management's tendency and personnel's motivation have positive significant relationship with fulfillment of corporative promises given to customers.

There are also four sub-hypotheses associated with the main hypothesis as follows,

1. Proportional to their responsibilities, personnel's role has positive and significant relationship with fulfillment of the given promises to customers.

2. Behavior of personnel who initially contact to customers has positive and significant relationship with fulfillment of the given promises to customers.

3. Personnel's motivation is positively and significantly associated with fulfillment of the given promises to customers.

4. Intimate communication among management and personnel has positive and significant relationship with fulfillment of the given promises to customers.

\section{Research Theoretical Bases}

\subsection{Importance and value of brand for B2B enterprises}

Many industrial marketers consider developing of the brand of a Trade Name only as a variant marketing cost that suffers from highly failure risk. This issue may not often strike in personnel's mind in an enterprise as well. However, do they have really an alternative and right to choose? Is nomination of a particular brand under industrial conditions as important as under consuming circumstances? Climate of industrial marketing is so fleeting and variable that those businesses, which could not adapt themselves to the new conditions essentially lay behind and far from this contest. Merging industries, loosing global economy and alternative products on the market are some of competitive effective factors. Within several increasingly competitive environments, it is no longer enough to supply and to deliver high quality services and products by determination of a certain trade name. In addition, brand and acquisition of a favorable competitive niche in market and businesses may make themselves distinct from this group by their achievement.

There are various strong factors, which have converted creation and building of industrial trade name and brand into a very crucial factor. Very interestingly, major factors have increased trade name and brand in consuming markets and it is getting clear in industrial markets that this point is very surprising to ignore importance of name branding in industrial market. These factors are divided into three general categories: 
1- Extension of similar services and products

\section{2- Progressively increasing complexity}

3- Unbelievable price pressure (Kotler \& Pfoertsch, 2007)

This point may be noted that trade signs and their power are more important in industrial marketing (B2B). Customer's sensitivity is very high and its flexibility at low level where a very little amount of carelessness may lead to thwarting all marketing efforts (Sutton \& Klein, 2006).

The recent studies, which have been conducted by McKinsey and MCM, indicate the importance and significance of trade name and brand in various industrial markets. They reviewed integrated performances of trade name and brand with respect to their importance and significance in an industrial environment and showed them. Therefore, the foremost performances of trade name and brand are as follows:

1- Improvement of information efficiency: The branded products may facilitate collection and processing of information regarding a certain product for customer further.

2- Risk reduction: Trade name and brand may contribute to guarantee and justification of purchase decision in industrial markets since industrial buyers are highly interested in avoiding risk.

3- Drawing an image from benefits and value- added: In an industrial environment, the created value added along with trade name and brand are not usually placed in position of totally distinctive values. In addition, the presence of this issue may be essentially important since through a certain trade name and brand we may introduce and announce not only our personnel but also the enterprise totally to the world (Kotler \& Pfoertsch, 2007).

Similarly, Industrial Enterprises (B2B) as providers for products and services in industrial marketing tend to acquire competitive advantage through adoption strategic development of brand value in order to survive in the arena of world competition and they may acquire profits like consuming markets by investment in this regard (Samiei nasr et al., 2010). Two variables of loyalty and trust are the paramount factors for creation of value to industrial brand. It should be noted that creation of value is not solely sufficient for a brand and industrial marketers should convert brand value into communication efficiency among buyers and providers (Han \& Sung, 2008).

\subsection{Brand Promise}

Brand promise is like a framework based on which distinct and related experience with brand are interpreted for customer by the enterprise in several times and places and certain situations (Light \& Kiddon, 2009). In a book called Brand Glossary and in definition of Brand Promise, Sieston argues that brand promise draw an image from mutual nature of relationship among the given brand with its audiences (Swystun, 2006). Brand promises often display themselves within the framework of products functional characteristics, experiences, feelings, emotions resulting from purchase of brand, possession of different personalities versus buying and acquisition of distinct characteristics of products from buying its certain brand (Light \& Kiddon, 2009). Of characteristics of an appropriate promise given for a brand is that the promised brand have some properties like adjustment with customers’ requirements, continuity, and customer- orientation (De Chernatony, 2010).

\subsection{Brand Promise System}

Brand promise system is a purposeful effort based on which brand promises are presented proportional to hierarchy of requirements and the needed adjustments to be exerted if it requires. With respect to constant changes in customers' needs and importance of adjusting brand promises to such variations, brand responsible managers in modern enterprises will inevitably review three basic aspects in designing of their brand promises where the first aspect is associated with creation and 
design of brand promises. At second aspect, way of delivery of such brand is purposed and in third aspect, way of maintenance and retaining of such brand promises successfully is discussed. Thus, in fulfillment of these three basic aspects for the given promises by corporative brand, enterprises shall establish direct relationship with customers and constantly evaluate percentage of efficiency in each of these promises and make the necessary corrective measures in this regard (Pringle, 2008).

\subsection{Cycle of brand promise delivery}

Enterprise- customers' relationship often forms regarding brand promise. Brand promises are passed often through a four- step route that is called as "Cycle of brand promise delivery".

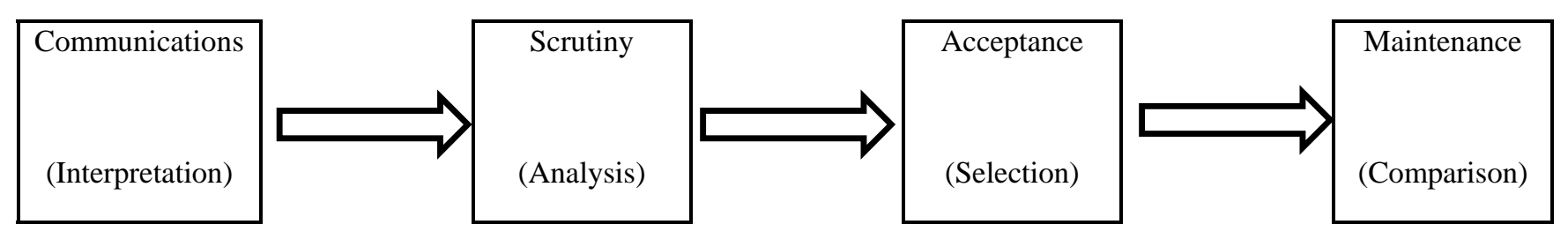

Fig. 1. Cycle of brand promise delivery (Samiei nasr et al., 2010)

1- Communications: (Promise is conveyed to consumer)

2- Scrutiny: (Consumer analyzes this promise)

3- Acceptance: (Consumer accepts the promise)

4- Maintenance: (Consumers continues comparison this promise with other items and in the case adjustment or non- adjustment of this promise, may make decision to become loyal to leave away from the given brand) (Samiei nasr et al., 2010)

\subsection{Role of Brand Promise in acquisition of competitive advantage}

After delivery of the promise to customer by an enterprise, a localized distinction is created in customer's mind. This causes the customer to buy the product and following this trend, fulfillment of the given promise to customer by the enterprise leads to creation of trust in customer and such trust will be followed by customer's satisfaction with the bought brand. According to several scientific studies, the major portion of customer's loyalty to a certain brand returns to their satisfaction with purchase of the given brand. The resultant satisfaction at former stage will be led to customer's loyalty to this brand. This also causes a loyal customer to create high profit for the enterprise because of the more stable relationship established with this brand in addition to acquisition of numerous benefits from purchase of the brand (Samiei nasr et al., 2010).

\subsection{Role of personnel's motivation in fulfillment of brand promise}

In order to manage to take step toward acquisition of stable competitive advantage, industrial organizations are required to provide necessary motivations for manpower in their organization distinctively versus their rival. Today, by giving distinct services to customers, manpower will cause improving brand in the organizations where motivation is one of the key factors in this regard. By intensifying the competition in commerce and growingly technological changes as well as increasing power and right of selection for customers, those enterprises will succeed that more duly comprehend, detect and respond to customers' expectations and the related values, more appropriately (Wang \& Liao, 2007). Through entrance path for brand supply, personnel are expected to revitalize the brand and act personally as brand agents. Brand is created in interaction between 
personnel and customers and this requires personnel's commitment to brand at high level. The greatest promotional campaigns will be effective only when personnel of an organization can induce a positive sense of their brand in customers (Heding et al., 2008).

Even though the personnel possess the sufficient motive, in the organization they could not meet customers' requirements and expectations against buying brand if they have not appropriate information regarding brand promises. This should be done by holding constant training courses for personnel and through interpretation of this issue and way of fulfillment of such promises to customers (Samiei nasr et al., 2010). Additionally, personnel's system, which is considered as one of their motivation factors in an organization should be designed based on the rate of fulfillment of brand promises by them to customers. Under such conditions in corporative reward system, some efforts should be taken into consideration in order to be made so that to attach some remarkable differences among committed personnel to brand promises and non- committed employees (Samiei nasr et al., 2010).

\subsection{Role of management in fulfillment of brand promise}

Support from team of Board of Directors and managing director is a key factor in establishment and fulfillment of brand promises inside and outside the enterprise (Samiei nasr et al., 2010). If corporative high rank teams are not committed to the given promises by enterprise's brand, then no one can also expect from other personnel to be abided by such promises. (Daye \& Vam Auken, 2010).

Furthermore, according to the results of recent studies, the higher degree of correspondence exists among organizational culture and appropriate brand personality, the greater success will result in brand strategies. This culture should be started from organizational higher levels and by observance of behavioral principles and brand personality via members of Board's team and managing director. As a result, if authenticity of brand is considered as one of characteristics of corporate brand personality then Board's team and managing director should behave honestly to personnel, customers and other beneficiaries totally (Samiei nasr et al., 2010)

\section{Methodology}

This study is intended to analyze role of management's tendency and personnel's motivation in fulfillment of corporative promises given to customers. The current investigation is a field study in terms of technique of gathering information, and it is a survey in terms of descriptive execution and developmental and applied type based on its goal. In this study, statistical population comprises of personnel of TAM Iran Khodro Company including managers and employees, who are totally 450 out of them 206 respondents, have been elected randomly in this population as final sample based on Morgan’s Sample Size Table.

\subsection{Analysis of Information}

To collect information in this study, a questionnaire, which designed by the researchers, was used. With respect to 40 participants in primary sample, reliability value of this questionnaire was calculated as 0.905 by Cronbach's Alpha Coefficient. Since this value is greater than 0.7 so reliability of questionnaire is demonstrated. Validity of the given questionnaire has been confirmed by means of comments from expert masters and the relevant specialists in this field.

\subsection{General Information from Respondents}

After conducting several reviews on descriptive statistics, general information from respondents is as follows: 


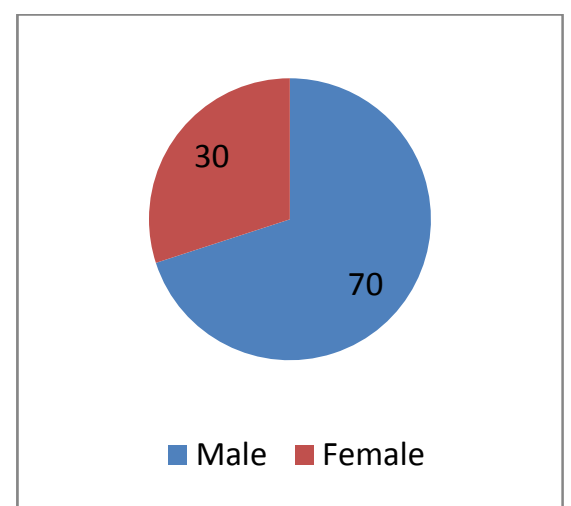

Gender

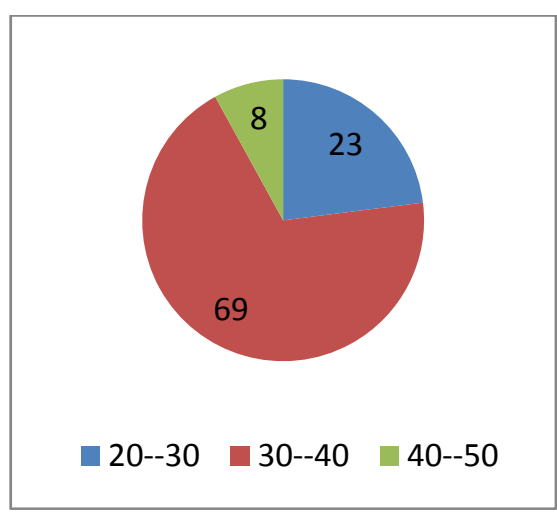

Age

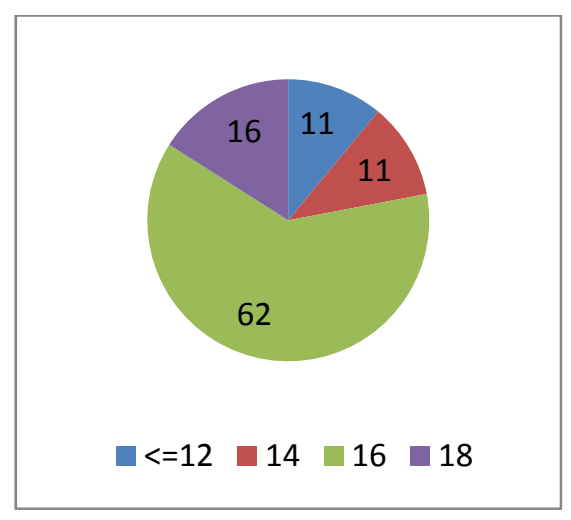

Years of education

Fig. 2. Personal characteristics of the participants

As we can observe from the results of Fig. 2, most participants are middle aged male oriented who have had some university educations.

\section{Information Analysis Tools}

To analyze the role of management's tendency and personnel's motivation in fulfillment of corporative promises given to customers, these data were gathered by researchers via designed questionnaire by them and then they were collected and reviewed and analyzed by means of Spearman's Correlation and Multiple Regression Tests.

\section{Table 1}

Analysis of Hypotheses

\begin{tabular}{|c|c|c|c|c|c|}
\hline $\begin{array}{c}\text { Research } \\
\text { Hypotheses }\end{array}$ & Hypothesis & $\begin{array}{l}\text { Spearman's } \\
\text { Correlation } \\
\text { Coefficient }\end{array}$ & Significance & $\begin{array}{c}\text { Significant at } \\
\text { level }\end{array}$ & Result \\
\hline Major Hypothesis & $\begin{array}{l}\text { Management's tendency and personnel's } \\
\text { motive have positive significant } \\
\text { relationship with fulfillment of } \\
\text { corporative promises given to customers. }\end{array}$ & 0.427 & 0.000 & 0.1 & $\begin{array}{c}\text { Proof of } \\
\text { Hypothesis }\end{array}$ \\
\hline Minor Hypothesis I & $\begin{array}{l}\text { Proportional to their responsibilities, } \\
\text { personnel's role has positive and } \\
\text { significant relationship with fulfillment } \\
\text { of the given promises to customers. }\end{array}$ & 0.398 & 0.000 & 0.1 & $\begin{array}{c}\text { Proof of } \\
\text { Hypothesis }\end{array}$ \\
\hline Minor Hypothesis II & $\begin{array}{l}\text { Behavior of personnel who initially } \\
\text { contact to customers has positive and } \\
\text { significant relationship with fulfillment } \\
\text { of the given promises to customers. }\end{array}$ & 0.283 & 0.002 & 0.1 & $\begin{array}{c}\text { Proof of } \\
\text { Hypothesis }\end{array}$ \\
\hline Minor Hypothesis III & $\begin{array}{l}\text { Personnel's motivation has a positive } \\
\text { significant relationship with fulfillment } \\
\text { of the given promises to customers. }\end{array}$ & 0.324 & 0.000 & 0.1 & $\begin{array}{l}\text { Proof of } \\
\text { Hypothesis }\end{array}$ \\
\hline
\end{tabular}

\section{Table 2}

Analysis of hypotheses by means of multiple regressions

\begin{tabular}{ccccc}
\hline Estimated Standard Error & $\begin{array}{c}\text { Determination Coefficient } \\
\text { of Adjustment }\end{array}$ & Determination Coefficient & $\begin{array}{c}\text { Multiple Correlation } \\
\text { Coefficient }\end{array}$ & Model \\
\hline 0.98126 & 0.390 & 0.396 & 0.629 & 1 \\
\hline
\end{tabular}

\subsection{Predictor variable with constant coefficient for Management's tendency and personnel's motive}

According to Table 2, variables of management's tendency and personnel's motive are associated with the fulfillment of corporate promises given to customers with value of 0.629. Column of determination coefficient suggests that Model 1 is final model at 0.396 . Variance of fulfillment of corporate promises may be explained by variable of management and personnel's interest. 
Table 3

Regression Coefficients and T-Test

\begin{tabular}{ccccc}
\hline Variables & Variance Coefficient & $\begin{array}{c}\text { Standard } \\
\text { Coefficient Error }\end{array}$ & Coefficient Error & t-value \\
\hline $\begin{array}{c}\text { Fixed Value } \\
\text { Management's tendency and } \\
\text { personnel's Interest }\end{array}$ & 2.961 & 0.694 & 0.265 & 0.629 \\
\hline
\end{tabular}

The results derived from multiple regressive analysis indicate that variable of management's tendency and personnel's motive, as a predictor variable, has the appropriate criterion to enter into regressive final equation to explain fulfillment of corporate promise given to customers. The results of Table 3 show regression coefficients and t-test to examine these coefficients and significance level for each of them and column of standard coefficients also indicates this fact by changing value of a standard deviation in variable of management's tendency and personnel's motive, it varies up to 0.629 in fulfillment of corporate promise given to customers. Finally, according to results came from the conducted multiple regressions, regressive equation is as follows:

$y=0.271 \quad$ (Management 's tendency and Personnel 's Motivation ) + 2.961

\section{Conclusion}

We have presented an empirical investigation to study the effects of management tendency on building an appropriate brand on market. The study has accomplished in an Iranian firm and the results have confirmed that Management's tendency and personnel's motive had positive significant relationship with fulfillment of corporative promises given to customers. In addition, the study has confirmed that personnel's role had positive and significant relationship with fulfillment of the given promises to customers. We have also determined that employees' behaviors who initially contact to customers had positive and significant relationship with fulfillment of the given promises to customers. In addition, employees' motivation had a positive significant relationship with fulfillment of the given promises to customers. Finally, Intimate communication among management and personnel provided positive and significant relationship with fulfillment of the given promises to customers.

\section{Acknowledgement}

The authors would like to thank the anonymous referees for constructive comments on earlier version of this paper.

\section{References}

Abbasi, H., Abbasi, H., Faraji, A \& Hajirasouliha, M. (2014). Investigating the effects of organizational culture on brand promise. Management Science Letters, 4(5), 1039-1042.

Azad, N., Hozouri, S., Zarifi, S \& Khodashenas, Y. (2013). A factor analysis to detect factors influencing building national brand. Management Science Letters, 3(3), 777-782.

Aziziha, H., Mousavi, S., Tabatabaee, S \& Khodsetan, A. (2014). Investigating the effect of different conflict management strategies on brand promise: A case study of banking industry. Management Science Letters, 4(1), 1-4.

De Chernatony, L. (2010). From Brand Vision to Brand Evaluation: The Strategic Process of Growing and Strengthening Brands. Routledge.

Daye, D., \& Vam Auken, B. (2010). 10 keys to Aligning Organizations and Brand Promises.

Kotler, P., \& Pfoertsch, W. (2007). Being known or being one of many: the need for brand management for business-to-business (B2B) companies. Journal of Business \& Industrial Marketing, 22(6), 357-362.

Han, S. L., \& Sung, H. S. (2008). Industrial brand value and relationship performance in business markets-A general structural equation model. Industrial Marketing Management, 37(7), 807-818. 
Heding, T., Knudtzen, C. F., \& Bjerre, M. (2008). Brand management: Research, theory and practice. Routledge.

Light, L., \& Kiddon, J. (2009). Six rules for brand revitalization. Learn how companies like McDonald's can re-energize their brands, Arcature LLC.

Pringle, H. (2008). Brand immortality: How brands can live long and prosper. Kogan Page Publishers.

Putnam, L. L., \& Wilson, C. E. (1982). Communicative strategies in organizational conflicts: Reliability and validity of a measurement scale. Communication Yearbook, 6, 629-652.

Samiei nasr, M., Alavi, S. M., \& Najafi Siahroodi, M. (2010). Secret of success of the world's top brands - twelve key characteristics of successful brands. Publisher: Sadeghpoor, Mahmoud (In Persian).

Sutton, D., \& Klein, T. (2006). Enterprise marketing management: the new science of marketing. John Wiley \& Sons.

Swystun, J. (Ed.). (2006). The brand glossary. Palgrave Macmillan.

Wang, Y. S., \& Liao, Y. W. (2007). The conceptualization and measurement of m-commerce user satisfaction. Computers in human behavior, 23(1), 381-398. 